\title{
Developing Guideline for Risk Management of Tunnel Construction in Ethiopia
}

\author{
Nigussie Hailemariam Gebremeskel, Henok Fikre Gebregziabher \\ Addis Ababa Institute of Technology, Addis Ababa University, Addis Ababa, Ethiopia \\ Email: Nigussie.h@gmail.com
}

How to cite this paper: Gebremeskel, N.H. and Gebregziabher, H.F. (2021) Developing Guideline for Risk Management of Tunnel Construction in Ethiopia. Open Journal of Safety Science and Technology, 11, 171-183. https://doi.org/10.4236/ojsst.2021.114012

Received: September 29, 2021

Accepted: December 20, 2021

Published: December 23, 2021

Copyright (อ 2021 by author(s) and Scientific Research Publishing Inc. This work is licensed under the Creative Commons Attribution International License (CC BY 4.0).

http://creativecommons.org/licenses/by/4.0/ (c) (i) Open Access

\begin{abstract}
This paper is concerned with the current tunnel practices in Ethiopia, the main challenges and risks which were associated with tunneling, risk assessment and controlling measures. In this paper the qualitative risk analysis is performed based on the surveyed data from the tunnel experts and other professionals participated on the tunneling work. The qualitative risk analysis has been conducted as an input for the risk matrix analysis method. The qualitative analysis incorporates risk identification, risk classification, risk ranking, risk responding and risk monitoring mechanism. So, based on the qualitative analysis made and the result, those risks which occurred in the tunneling phase are ranked and controlling mechanism is developed. Accordingly, a guideline of risk management for tunneling work has been developed by referring different standards and based on the current tunnel practices in Ethiopia. The study helps to easily understand the most risks which are associated with tunneling and the risk controlling mechanism. This gives guidance to those who will be participated in the tunnel project for tunneling risk management throughout the entire project implementation.
\end{abstract}

\section{Keywords}

Tunneling Risk, Risk Management, Qualitative Risk Analysis, Risk Matrix, Guideline

\section{Introduction}

The Ethiopian government has been undertaking several transportation projects which aim to enhance the transportation network within the country by connecting to adjacent country and ports. These transport projects involve tunneling works due to the terrain of the country. Projects which incorporate tunneling construction are complex in nature, and encompass various types of risk 
throughout the project life cycle [1].

In Ethiopia, projects involving tunneling work are introduced but there is no well-organized risk management guideline in order to manage the risks. This makes difficult to easily understand risks during the tunnel construction. Therefore, the study attempts to develop a guideline that aims to overcome this problem and to give an insight for further study.

So, developing a guideline for risk management is a basic tool for planning and controlling tunneling projects risk. Risks can affect all parties involved as well as those not directly participated in the tunneling project. Risks can occur due to the inherent uncertainties of the ground and groundwater conditions. Because the risks that happen there might be a significant cost overrun and delay as well as environmental risks. Risks can be handled in different methods directly or indirectly using engineering skills, but at this time improving systematic and well-organized risk management techniques are important [1]. The importance of risk management is from the early stages of a project, where major decisions such as choice of alignment and selection of construction methods can be influenced. The majority of past research on tunneling risk management had focused on risk identification and risk analysis [1] [2] [3]. Few research projects have studied risk response in tunnel construction [4].

The study carried out qualitative risk analysis for the risks occurring during tunneling and based on the analysis risks which are identified, ranked and control measures are developed as shown in Figure 1. These controlling measures are studied for all tunneling phases and this can be used as a guideline for future tunneling work.

The structure of this paper is organized into 6 sections. Section 1 is about the introduction part, and Section 2 discusses the literature review related to current tunnel practices in Ethiopia including the risk management from other researches perspectives. Section 3 describes the Methodology used to analysis the data and the analysis results are discussed in Section 4. In Section 5 describes the developed guideline for risk management in tunneling. Finally, Section 6 summarized the conclusion and recommendation part.

\section{Tunnel Practices and Risk Management in Ethiopia}

In Ethiopia, modern tunnel construction has been recently used in hydropower projects, road projects, and railway projects. Tunnels are recent practices for Ethiopia. This is because it asks advanced technology and big capital. The AKH railway tunnels are constructed by Conventional Excavation Method [5] as shown in Figure 2 and Hydro Power Tunnels by Tunnel boring Machine (TBM) [6] and using mechanical excavation.

Thus, tunneling projects are constructed and under construction in Ethiopia, but there is no well-organized risk management guideline to control the risks from happening. To manage the risks firstly it is important to understand the risk types associated with tunneling works, and secondly the cause of the risks by referring to the past historical data. 


\begin{tabular}{|c|c|}
\hline $\begin{array}{l}\text { Design Risk } \\
\text { Mitigation } \\
\text { Measures }\end{array}$ & $\begin{array}{l}\text { Detail feasibility study/consulting with the national bodies } \\
\text { Reviewing geological investigation } \\
\text { Selecting the proper tunnel design method } \\
\text { Study on the previous } \\
\text { Using proper project delivery system }\end{array}$ \\
\hline $\begin{array}{l}\text { Construction } \\
\text { Risk Mitigation } \\
\text { Measures }\end{array}$ & $\begin{array}{l}\text { Selecting appropriate construction method \& technology } \\
\text { Installing advanced protective barriers\& warnings } \\
\text { Providing training program } \\
\text { Using safety equipment's } \\
\text { Daily monitoring the excavation } \\
\text { Supply adequate ventilation \&lighting } \\
\text { Inspecting installed ground supports } \\
\text { Smooth blasting and arranging it in the absence of workers } \\
\text { Scaling to minimize risks of rock falls } \\
\text { Correct procedure \& supporting technique must be used } \\
\text { Limiting underground chemical storage } \\
\text { Checking and maintaining excavating machines on time }\end{array}$ \\
\hline $\begin{array}{l}\text { Risk Mitigation } \\
\text { Measures during } \\
\text { operation phase }\end{array}$ & $\begin{array}{l}\text { Monitoring traffic flow by using signs, alarms, sensors and } \\
\text { video cameras } \\
\text { Installing effective communication equipment's } \\
\text { Providing adequate ventilation and lighting system } \\
\text { Continuous deformation and settlement observation } \\
\text { Installing proper drainage system } \\
\text { Providing fire protective equipment }\end{array}$ \\
\hline
\end{tabular}

Figure 1. Summary of tunneling risk controlling measures.

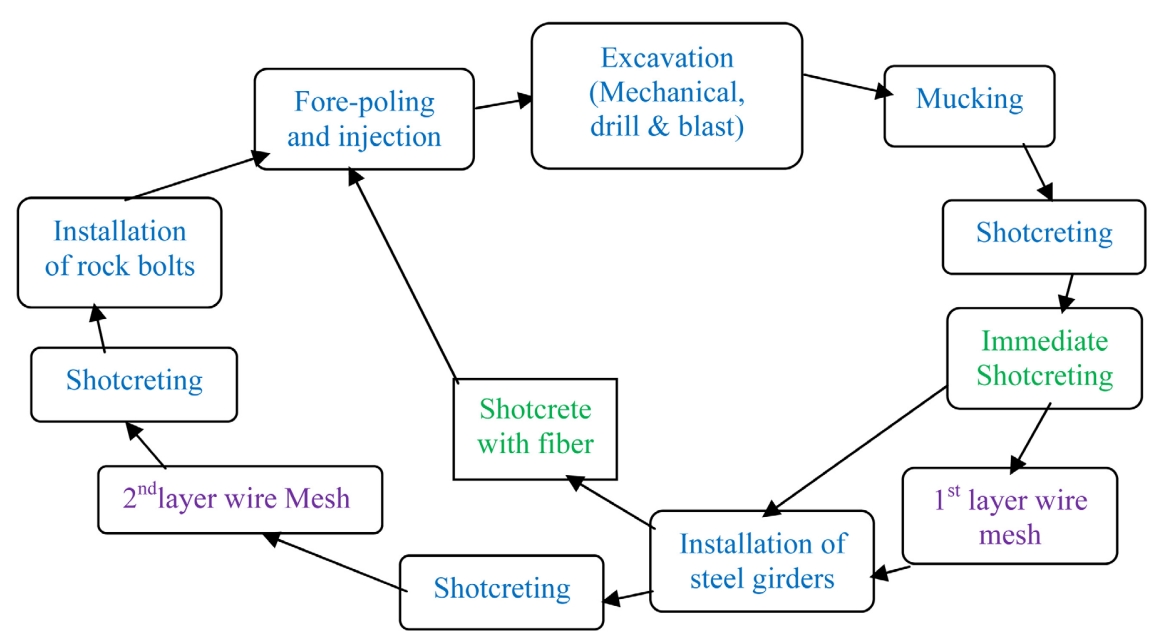

Figure 2. Working flow of tunnel excavation and supporting operations.

\subsection{The Common Tunnel Failures and Remedial Measures Taken}

Tunnel failure is an unanticipated disastrous consequence of an event that badly affects the physical safety of the underground structure. The most frequently reported tunnel construction failures are cave-in collapses, tunnel flooding, portal instability or excessive deformation of the tunnel tube, and the overburden

[7] [8]. The main Causes for tunnel failure are:

- Uncertainty of the ground condition or presence of weak geological formation;

- Earthquake when the tunnel not deep and at high earthquake zones;

- Inappropriate explosive material storage and usage; 
- Pumping action of water;

- Excavation method applied;

- Type of equipment and experience of working;

- Applied tunnel supporting type;

- Human errors/lack of skills;

- Several unwanted external events/factors.

The main failures faced during tunnel construction in Ethiopia include; face collapse, construction failure, TBM damaging, rock and shotcrete falling, seepage problem and Noise and dust pollution [7] [9].

The possible cause for the failure was due to the choice of construction method, lack of monitoring, the existence of weak geological formation, stress increased due to the additional excavation, drainage problem and delay in the installation of tunnel support which was the similar reason as different studies indicated [9] [10].

The mitigation measures taken after the failures include; the falling mass was mucked out, support was provided, changing the tunnel alignment, TBM was dismantled and maintained, drainage holes provided and providing safety barriers. The risk or failures causes death, injury to workers, damage to working machines, delay to the project completion time, financial loses, unsafe working condition and generally has an impact on the project goals [7] [9].

\section{Risk Categories during Tunnel Phases}

Tunneling risk can be described as exposure to the possibility of favorable or unfavorable effects on the tunneling project's goal such as construction cost, time, or quality as a consequence of a possible or an unforeseen incident.

The most common risks associated with tunnel construction which are mentioned in Table 1 include; design risk, construction risk, project management risk, external risk, right of way risk, environmental risk, and organizational risks. The importance of classifying the risk types into correspondence categories is to clearly understand the risk factors and to easily manage them.

\subsection{Risk Management for Tunnel Construction}

Risk management in the tunnel construction project is a comprehensive and systematic way of identifying, analyzing and responding to risks to achieve the project objectives [11] Figure 3. Risk management also involves; processes, tools, and techniques that will help the tunnel expertise to minimize the probability and consequences of adverse events to the overall project objectives of cost, time, scope and quality.

To analyze risks there are different tools such as qualitative, semi-quantitative, or quantitative methods. It is very necessary to revise the risk analysis during the project life cycle. When the team repeats risk analysis for individual risks, trends may be developed. These good trends lead to understanding whether the developed risk mitigation plan is working or not. 


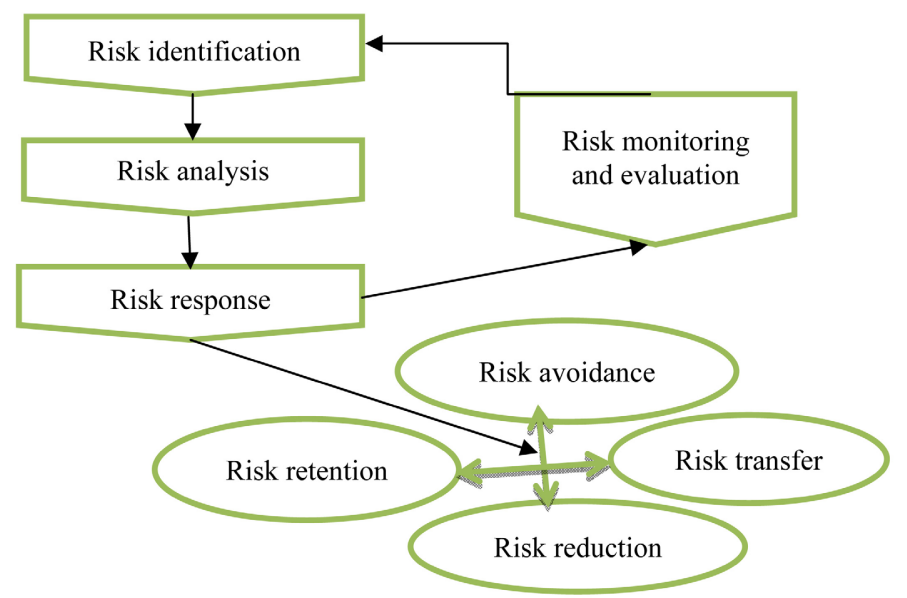

Figure 3. Iterative risk analysis procedures.

Table 1. Risk breakdown structure in tunnel construction.

1) Design

Related Risks

2) Construction

Related Risks

3) Project

Management

Risks

4) Environmental

Related Risks

5) Right of

way Risks

6) Organization

Related Risk

External

Factors Risks
D1) Design errors and omissions

D2) Design process takes longer than anticipated

D3) Stakeholders request late changes

D4) Failure to carry out the works based on the contract

C1) Cave-ins or excavation collapses

C2) Construction equipment failures

C3) Falling of excavated material

C4) Changing conditions - strata and stress field

fluctuations

C5) Tunnel instability - rock or earth falls and rock bursts

C6) High noise levels and vibration and dust

C7) Excessive seepage and ground water inflow

C8) Fire or explosion problem

M1) Failure to comply with contractual quality Requirements

M2) contractor delays,

M3) Scheduling errors

M4) Project team conflicts

En1) Environmental analysis incomplete

En2) Air contamination or oxygen depletion

En3) Incomplete environmental analysis

R1) Improper \& delay in resettlement of the land owners

R2) Conflict with the land owners

O1) Inexperienced workforce and staff turnover

O2) Delayed deliveries

O3) Lack of protection on a construction site

Ex1) New stakeholders emerge and request changes

Ex2) Public objections/challenges

Ex3) Laws and local standards change

Ex4) Tax change

Ex5) Construction cost increasing 
According to Veerasak Likhitruangsilp research [1] an alternative risk-response measure for each risk type employed by tunneling contractors was selected, including risk-retention, risk-reduction, risk-transfer, risk-avoidance, and contingency allowance.

These risk response criteria were also applied by the tunneling contractor in Ethiopia. This is presented in the next sub section part 4.1.3.

The Awash-Kombolcha-Haragebeya railway project contractor (Yapi Merkezi) had a risk controlling mechanism during the construction phase. This international company Yapi Merkezi accomplished successfully the construction of the 11 tunnels because of the effective risk management system applied.

\section{Methodology}

This study gathered the data and information by using Questioner survey, interview and by reviewing research papers related to the study.

The qualitative risk analysis method was applied to this case and the analysis is performed based on the collected data by surveying method which is $82 \%$ of the distributed questioner were returned. The detailed discussion of the analysis is described in the next Section 4.

\section{Discussion on the Qualitative Risk Analysis Results}

In this paper presents qualitative risk analysis result and the applied risk-response criteria by tunneling contractors in Ethiopia. The qualitative risk analysis technique is applied in order to identify, categorize and ranking these risks occurred during the tunneling projects in Ethiopia. The input data was calculated by taking the average of the likelihood and impact value filled by the respondents. Based on these values and using the analysis procedure Risk matrix is developed as shown in Table 2. The risk response measures applied in the tunneling in Ethiopia were also described on the next subsection.

\subsection{Qualitative Risk Analysis Procedures}

Tunnel experts can easily understand the type risks in their respective field of

Table 2. Probability X impact risk matrix.

\begin{tabular}{|c|c|c|c|c|c|}
\hline \multirow{2}{*}{$\begin{array}{l}\text { Likelihood } \\
\text { [1 (rare) - } 5 \\
\text { (frequently)] }\end{array}$} & \multicolumn{5}{|c|}{ Impact [1 (very low) - 5 (very high)] } \\
\hline & 1 & 2 & 3 & 4 & 5 \\
\hline 5 & & & & & \\
\hline 4 & & & $\mathrm{C}_{6}$ & & \\
\hline 3 & & $\mathrm{D}_{2}$ & $\mathrm{M}_{3}$ & $\mathrm{O}_{1}, \mathrm{C}_{2}, \mathrm{C}_{4}, \mathrm{C}_{7}, \mathrm{Ex}_{5}$ & \\
\hline 2 & & & $\begin{array}{c}\mathrm{O}_{2}, \mathrm{M}_{2}, \mathrm{M}_{4}, \mathrm{En}_{1} \\
\mathrm{En}_{3}, \mathrm{C}_{3}, \mathrm{R}_{1}\end{array}$ & $\begin{array}{c}\mathrm{En}_{1}, \mathrm{M}_{1}, \mathrm{C}_{5}, \mathrm{C}_{8} \\
\mathrm{D}_{1}, \mathrm{D}_{4}, \mathrm{Ex}_{2}\end{array}$ & $\mathrm{C}_{1}, \mathrm{O}_{3}$ \\
\hline 1 & & & $\mathrm{D}_{3}, \mathrm{Ex}_{3}, \mathrm{R}_{2}, \mathrm{En}_{2}$ & $\mathrm{Ex}_{4}$ & \\
\hline
\end{tabular}


tunnel construction and share the assessments with their colleagues. At the same tunnel project, the criteria and naming used for levels of probability and impact are always the same.

The qualitative risk analysis is performed by applying the following steps [12] [13] [14] as shown in Figure 4.

\subsubsection{Risk Classification (Risk Breakdown Structure)}

Risk breakdown structure plays an important role in the risk management due to the high number and variety of risks that affects the tunneling projects [15]. So, in this study the risks are breakdown into seven main categories and each group has divided as shown in Table 1 . The probability and impact of the classified risks are described in quantitatively terms as very high, High, Medium and Low. The levels of probability and impact are assessed by questioner survey. The participants include tunneling experts and project team members.

\subsubsection{Developing Probability X Impact Matrix}

According the tunnel association group [16], a probability $\mathrm{x}$ impact matrix is developed that assigns a risk rating (low, moderate or high) to risks based on combining probability and impact scales of a risk on a project objective. The risk value is calculated by the equation, $R L=P^{\star} I$. The risk matrix developed in Table 2. is based on the experts' point of view and as the result indicates that most of the risks associated during construction of the tunnel are categorized into high risk level while most of the risks are assigned in the medium level and other external risks are grouped the low risk level. Therefore, the high risk level must be reduced to an acceptable level or different risk mitigation measures must be developed. The mitigation measures are summarized in next Section 5.

The result of the qualitative risk analysis is also presented by chart as shown below in Figure 5.

\subsubsection{Risk Treatment Criteria}

The risk matrix presented above Table $2 \&$ Figure 5 is intended as a basis for decision on acceptability for each hazard identified and by controlling the magnitude of the individual risk from the individual hazard, the total risk involved in the tunneling work will be managed [4]. The risk will be treated based on its ranked risk level, and the recommended risk treatment criteria are described in Table 3 below. According the surveying data collected, most of the tunneling

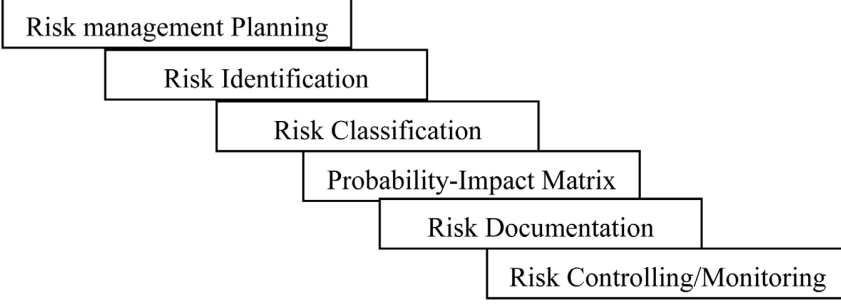

Figure 4. Qualitative risk analysis procedure. 


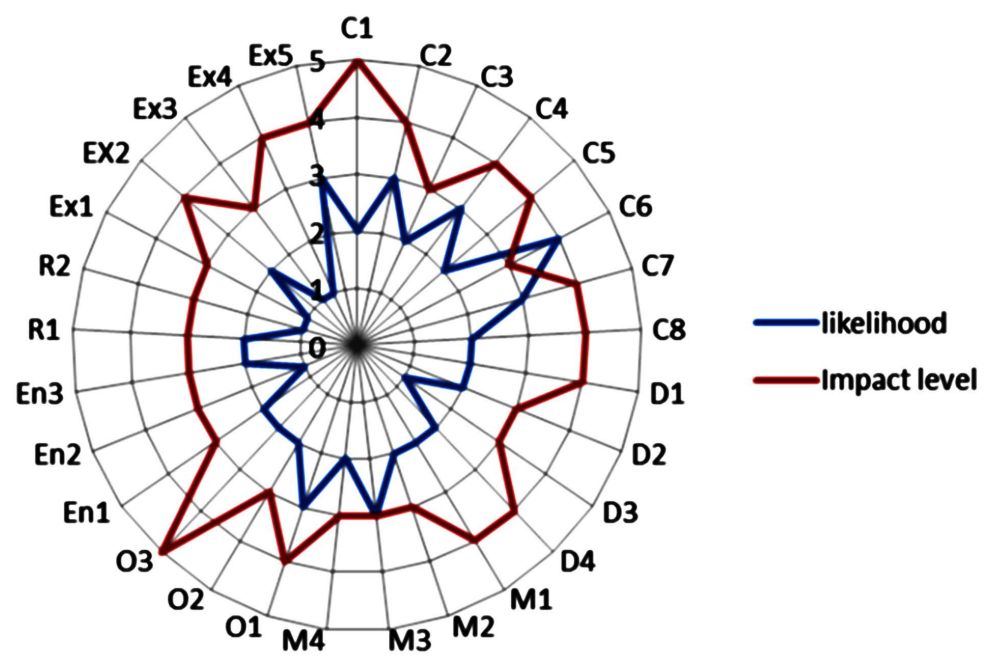

Figure 5. Qualitative risk analysis result.

Table 3. Risk treatment criteria.

\begin{tabular}{cc}
\hline Risk level & Treatment (Response Method) \\
\hline V. high Risk (Value $>15)$, Brown Colored & Avoid the risks (Risk avoidance) \\
High Risk $(10<$ Value $<15)$, Red Colored & $\begin{array}{c}\text { Reduce to the acceptable region } \\
\text { (Risk reduction) }\end{array}$ \\
Medium $(5<$ Value $<10)$, Yellow Colored & $\begin{array}{c}\text { Residual risk is tolerable if reduction } \\
\text { is impossible or (Risk transfer) }\end{array}$ \\
Low Risk (Value $<5)$, Green Colored & Tolerable risk, Risk reduction \\
& may not needed (Risk retention) \\
\hline
\end{tabular}

experts in Ethiopia selected; the risk reduction, risk retention, risk transfer and risk avoidance from their experience.

\section{Adopted Guideline for Tunneling Risk Management}

The guideline shows how risk management can be utilized throughout the tunnel phases implementation. Identification of risks resulting from the design and construction is an essential task early in the project [16]. It is very necessary to understand and allocate the responsibility and obligation of the parties involved in the tunnel construction. This is helpful to prepare and manage the risks that occurred during the tunneling phases. The responsibility of these stakeholders (owner, designers and contractors) is summarized as shown in Figure 6 below. In phase 1, the responsibility of establishing risk policy and caring out risk assessment is the owner's alone. In phase 2, the contractor has certain input to the tendering regarding the risk management, but still the owner the primary responsible party. In phase 3 , the contractor has the primary responsibility to establish and carryout risk management system. In phase 4, during commissioning time, the contractor has more responsibility and during the operation phase, the owner is the responsible party. It is important to note that the effective and 


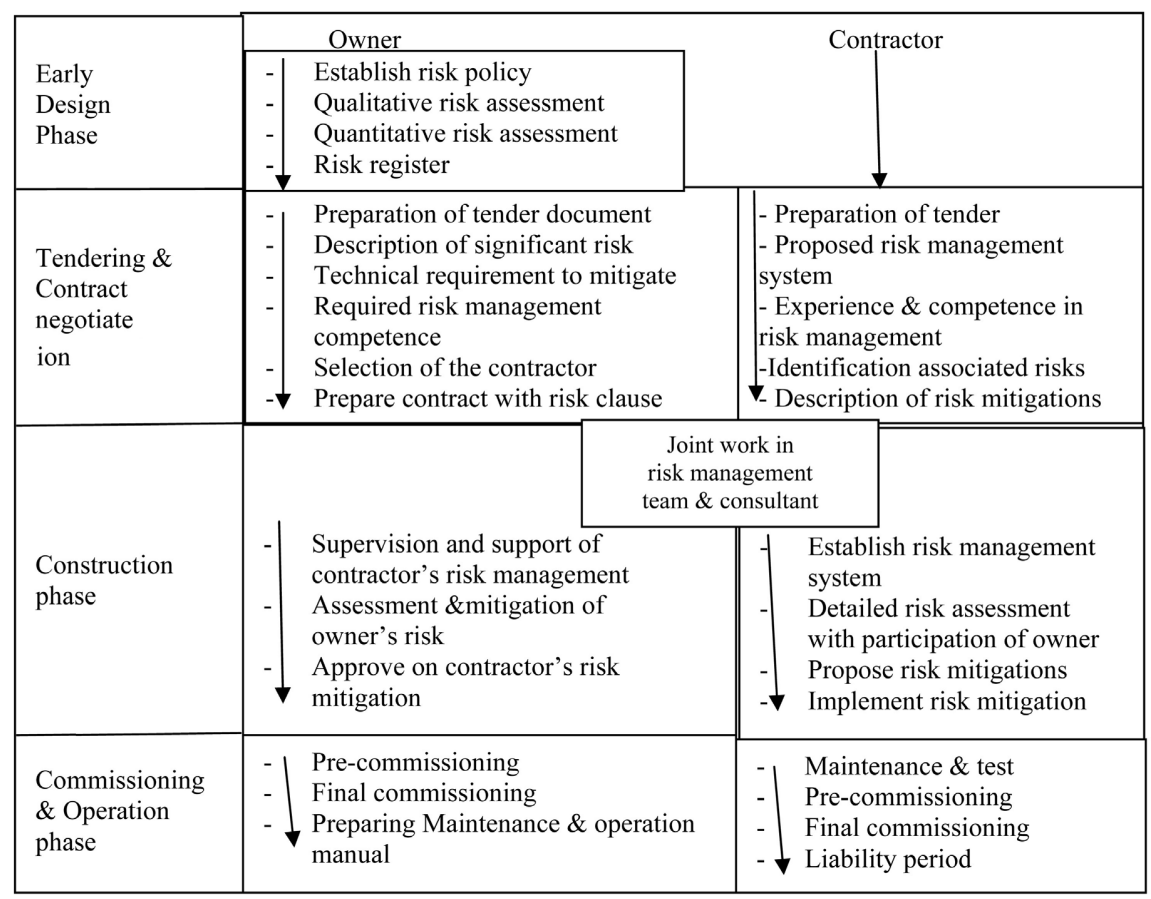

Figure 6. Risk management activity flow chart for owner and contractor.

successful risk management depends on the quality of the identified risk mitigating actions, experience and stake holders (Owner, designer, Contractor) cooperation. Risk management can't be achieved by system enforcement alone, but can be enhanced by the meeting and seminars [16].

In the early design stage and tendering phase, certain risks can be transferred either through contractually and insurance, others may be retained and some risks can be mitigated, but at the construction phase it is difficult to transfer the risks. So, it is necessary to minimize the risks during early phase of the tunnel project [15] [16].

\subsection{Adopted Controlling Measures during Tunneling Phases}

Based on the current tunnel practices in Ethiopia [6] [7] [9] and other researches [16] [17], this study attempts to generalize the mitigation techniques starting the early design phase, construction, and operation time. So, the most preferred and applied techniques to manage the risks which associated with tunnel construction phases are summarized in Figure 1.

\subsection{Adopted Guideline for the Tunneling Construction}

Different authors are studied the evaluation of the tunneling excavation method and tried to compare both the Conventional Excavation Method (CEM), and Tunnel Boring Machine (TBM) by their applicability, importance and challenges [18]. By learning from the lessons of current tunnel practices in Ethiopia [6] [7] [9] a guideline is developed. Therefore, to mitigate risks associated with tunneling; selecting an appropriate construction technique and excavation equipment 
depending on the ground investigation and tunnel type is very necessary. This adopted guideline is then indicated which type of technique is acceptable to apply or to avoid it depending on different factors. The selected factors, in this case are length, diameter, and ground condition of the tunnel Tables 4-6.

Notes:

$\checkmark$ This guidance should be used with conjunction to the chapter five

$\checkmark$ This guidance is developed based on reviewing related studies and current tunneling in Ethiopia

$\checkmark$ All manual excavation is categorized as "not acceptable" or "avoid" that is due to the unforeseeable underground risks, unsafe access and inadequate working space etc.

$\checkmark$ The designer should compile the three table while using in order to minimize the risks during tunneling

Definitions:

Acceptable-designers should undertake an assessment on the excavation technique and on the associated risk and specify the appropriate mitigation measures

Avoid-designers should undertake risk assessment to justify their decision from acceptable criteria. Contractors being asked to construct using this category should also seek advice from the planning supervisor/coordinator on the adequacy of their risk mitigation measures.

Table 4. Tunnel excavation techniques vs its length.

\begin{tabular}{cccccc}
\hline Excavation Technique & $\mathrm{L}(\mathrm{km})$ & $<0.3 \mathrm{~km}$ & $0.5 \mathrm{~km}$ & $1.0 \mathrm{~km}$ & $>1.5 \mathrm{~km}$ \\
\hline Manual Excavation & Acceptable & Avoid & Not acceptable \\
Plant/Mechanical & & Acceptable & & Avoid \\
TBM Machine & Avoid & \multicolumn{3}{c}{ Acceptable } \\
Drill \& Blast & Avoid & \multicolumn{3}{c}{ Acceptable } \\
\hline
\end{tabular}

Table 5. Tunnel excavation techniques vs the ground condition.

\begin{tabular}{cccc}
\hline Excavation Technique & Soft ground & Varity ground & Hard rock \\
\hline Manual Excavation & Avoid & \multicolumn{2}{c}{ Not acceptable } \\
Plant/Mechanical & \multicolumn{2}{c}{ Acceptable } & Avoid \\
TBM Machine & \multicolumn{2}{c}{ Acceptable } & Avoid \\
Drill \& Blast & Avoid & Acceptable \\
\hline
\end{tabular}

Table 6. Tunnel excavation techniques vs its diameter.

\begin{tabular}{|c|c|c|c|c|}
\hline Excavation Technique & $<1.5 \mathrm{~m}$ & $3 \mathrm{~m}$ & $7 \mathrm{~m}$ & $>9 \mathrm{~m}$ \\
\hline Manual Excavation & Avoid & \multicolumn{3}{|c|}{ Not acceptable } \\
\hline Plant/Mechanical & \multicolumn{3}{|c|}{ Acceptable } & Avoid \\
\hline TBM Machine & Not acc & & acceptable & Not acceptable \\
\hline Drill \& Blast & Avoid & & Accepta & \\
\hline
\end{tabular}


Not acceptable-the designer should specify another alternative tunneling technique

\section{Conclusion}

As the qualitative risk analysis result, and other research papers [1] [7] [16] indicate that most challenges and tunneling risks are occurring during excavation phase, this is because of the uncertainty of the ground and fluctuation of the stress and deformation of the ground condition. Therefore, selecting the appropriate excavation method, technology and continuous monitoring is the best risk controlling measures. As we see from Figure 2, the tunnel construction practice in Ethiopia, the railway tunnels are constructed by mechanical \& Drill \& Blast method which is the accurate technique to control the weak zones during excavating the surface [6]. So, in these railway tunnels, due to the applying of the appropriate construction method and well organized risk controlling mechanisms used there was no potential risk occurred. Those Hydropower tunnels (Gilgel Gibe 2, 3 and Tana Beles) which were constructed by the TBM machine had faced tunnel collapse, injuries and loss of life as well because of the inaccurate standup time calculation, presence of weak geological formation and the applied construction method [7] [9].

So, this study indicates that to manage the risk of tunnel construction effectively and efficiently, the contractor should have a guideline for risk management of tunnel construction.

As this study shows that having well organized safety departments like that of Awash-Kombolcha-Haragebeya railway project, risks are reduced as the required level. The Yapi Merkezi Contractor had clearly registered risk assessment plan and management policies, which helped them to control risks from occurring [6].

Finally, based on the performed qualitative risk analysis, risks are identified and a risk matrix is developed for the Awash-Kombolcha-Haragebeya railway tunnels.

Based on the level of risk, risk response is a key component of risk management in tunnel construction, which involves choosing the appropriate control measures to eliminate or reduce the chance of occurring or consequence of the risk.

It was found that the most commonly selected and used risk-response measures were risk-reduction, risk-retention, risk-transfer, and risk-avoidance. This order was almost similar to the study made by Veerasak [1] in Tunneling project in Thailand. So, these risk responding techniques are important to apply during the tunneling duration.

In general, a simplified guideline is developed by comparing with similar related research papers and other different country's guidelines [10] [15] [16], and this research will help to easily understand the tunnel practices in Ethiopia, risk types associated with tunneling, risk analysis, controlling techniques, and monitoring mechanisms etc. 


\subsection{Recommendation}

Even though tunneling risks are complex in nature it is necessary to manage (control) it in different means before happening or after occurring the risks. Therefore, risk controlling mechanism should be in systematic way of risk management process that is why developing guideline is mandatory in order to manage risks effectively, and this is the importance of this paper.

\subsection{Recommendation for Further Research}

Qualitative risk analysis is a general way of assessing risks but high level risks should be analyzed by quantitative risk analysis method and it is better to develop risk analysis models to manage risks in good manner.

So, performing quantitative analysis and developing software model for the risk analysis and risk management should be studied in next research.

\section{Acknowledgements}

The Author would like to thank Eng. Abdulkerim Mohamed project engineer of $\mathrm{AKH}$ project for facilitating site visit and availing the required document for this study. Also special thanks for Dr. Henok Fikre for his continuous follow up during the research preparation.

\section{Conflicts of Interest}

The authors declare no conflicts of interest regarding the publication of this paper.

\section{References}

[1] Likhitruangsilp, V. and Ioannou, P.G. (2012) Analysis of Risk-Response Measures for Tunneling Projects. Construction Research Congress 2012, West Lafayette, 21 23 May 2012, 258-266. https://doi.org/10.1061/9780784412329.027

[2] Duddeck, H. (1987) Risk Assessment and Risk Sharing in Tunneling. Tunneling and Underground Space Technology, 2, 315-317. https://doi.org/10.1016/0886-7798(87)90042-3

[3] Ghosh, S. and Jintanapakanont, J. (2004) Identifying and Assessing the Critical Risk Factors in an Underground Rail Project in Thailand: A Factor Analysis Approach. International Journal of Project Management, 22, 633-643.

[4] Choothom, S.A. (2006) Risk Allocation in Tunneling Contracts Using Tunnel Boring. Thesis, Chulalongkorn University, Bangkok. https://ur.booksc.eu/book/21385859/b847f8

[5] Baker, S.P. (1999) Risk Response Techniques Employed Currently for Major Projects. Construction Management and Economics, 17, 205-213. https://ideas.repec.org/a/taf/conmgt/v17y1999i2p205-213.html https://doi.org/10.1080/014461999371709

[6] AKH (2016) Report on the Tunnel Construction of Awash-Kombolcha-Haragebeya Railway Project.

[7] Antonio De Biase, R.G. (2007) Gibe II Tunnel Project-Special Designs and Measures Implemented to Face One of the Most Difficult Event in the History of Tunneling. 
[8] Cooke, J. (1975) Hazards in Tunneling and False Work. ICE Publishing, London.

[9] Tayachew, M. (2015) Design and Construction of Tunnels in Ethiopia. Thesis, The School of Graduate Studies of Addis Ababa, Addis Ababa.

[10] NSW (2006) Tunnel under Construction Code of Practice. https://www.safework.nsw.gov.au

[11] Špačková, I.O. (2012) Risk Management of Tunnel Construction Projects. Doctoral Thesis, Ing. Olga Špačková, Prague.

http://mech.fsv.cvut.cz/wiki/images/7/7a/PhD dissertation Spackova 2012.pdf

[12] Li, L. (2018) A Study on Enterprise Risk Management and Business Performance. Journal of Financial Risk Management, 7, 123-138. https://doi.org/10.4236/jfrm.2018.71008

[13] Boom, R. (2019) Financial Risk Management in Dutch SMEs: An Empirical Analysis. Journal of Financial Risk Management, 8, 55-72. https://doi.org/10.4236/jfrm.2019.82005

[14] Sookye, L. and Mohamudally-Boolaky, A. (2019) Effectiveness of Financial Risk Management Framework: An Analysis of the Mauritian Banking Sector. Journal of Financial Risk Management, 8, 106-124. https://doi.org/10.4236/jfrm.2019.82008

[15] Gafari, M.A. (2015) Identify and Analyze the Risks Involved in Tunnel Projects. Current World Environment, 10, 1102-1108.

https://doi.org/10.12944/CWE.10.Special-Issue1.129

[16] Søren Degn Eskesen, P.T. (2002) Guidelines for Tunneling Risk Management.

[17] ITIG (Insurance Members) (2006) A Code of Practice for Risk Management of Tunnel Works.

[18] Couto, J.P., et al. (2018) Risk Evaluation in Tunneling Excavation Methods. REMInternational Engineering Journal, 71, 361-369. 